This investigation was supported by a research grant $E-4075$ from the National Institute of Allergy and Infectious Diseases, U.S. Public Health Service.

Department of Microbiology,

University of Minnesota, Minneapolis.

1 Mefferd, jun., R. B., and Loefer, J. B., Physiol. Zool., 27, 115 (1954). S Smith, C. G., Lummis, W. L., and Grady, J. E., Cancer Res., 19, 843
(1959).

O Whiffen, A. J., J. Bact., 56, 283 (1948)

- Latuasan, H. E., and Berends, W., Rec. Trav. Chim., 77, 416 (1958).

Bradley, S. G., and Creevy, D. C., J. Bact., 81, 303 (1961).

- Kerridge, D., J. Gen. Microbiol., 19, 497 (1958).

\section{Identification of Purported Agaricus campestris Strains (NRRL 2334, 2335, 2336) as Beauveria tenella (Delacroix Siem.)}

Comparatrve morphological and physiological investigations were conducted with different European strains of the cultivated mushroom and with three strains of Agaricus campestris (NRRL 2334, 2335, 2336) from the Northern Regional Research Laboratory, Peoria, Illinois. These have been described as mutants arising from normal cultivated mushrooms under conditions of submerged culture ${ }^{1}$.

These strains differed greatly from the normal strains in substrate demand, speed of growth, mycelium yield, enzymatic qualities, and colony growth as well as in microscopic appearance on solid media and liquid culture. In addition, no fruiting bodies were produced ${ }^{1-7}$.

It is, however, improbable that these NRRL strains which appeared in 1948 in Humfeld's labora. tory during submerged culture experiments, and described by him as spontaneous mutants, could be mutants. The possibility that so many independent qualities were altered during one or few mutation steps is very remote. In my own experiments with an even larger selection of strains it was impossible to detect such mutants.

An exhaustive examination of these $N R R L$ strains in the Centraalbureau voor Schimmelcultures, Baarn, Holland, showed that under certain conditions a form of asexual reproduction occurred. The oval, smooth, hyaline conidiospores $(1.8-4.5 \mu \times 1.8-3.2 \mu)$ and oblong macrospores $(6 \cdot 6-9.4 \mu \times 2.4-3.2 \mu)$ arising thereby developed on sporogenous cells which were usually swollen and bottle-shaped.

According to my observations, these strains do not belong to the Basidiomycetes, but to the Fungi Imperfecti, family Moniliacese, genus Beauveria. Comparisons with authentic Beauveria strains confirmed the identity of the NRRL strains as members of the genus Beauveria.

A repetition of these investigations with $N R R L$ 2334, 2335, 2336 strains, again received from Peoria, and the agreement of my own findings with those from previous investigators, eliminated the possibility of an infection occurring since the first description of these strains ${ }^{2}$.

It was also confirmed that the Beauveria strains, like other Moniliaceae, were able to live saprophytically on the fruiting bodies of cultivated mushrooms. It is therefore possible that the Beauveria infection was carried with the inoculum (tissue-culture of mushroom fruiting bodies ${ }^{1,5}$ ) into the submerged cultures or entered the culture through some other agent. Probably the infection overgrew the slow-growing mushroom mycelium. Beauveria species are commonly encountered where mushrooms are cultivated ${ }^{8}$.
On the basis of these findings, it is not surprising that attempts to produce mushroom mycelium commercially in submerged culture with the strains NRRL 2334, 2335, 2336 have been abandoned because of the lack of the typical mushroom flavour in the mycelium harvested ${ }^{\theta}$.

Institut für Mikrobiologie der Universität,

Peter Molitoris Göttingen.

${ }^{1}$ Humfeld, H., Yearbook Agric., U.S. Dept. Agrie., 242 (1950/52).

${ }^{8}$ Humfeld, H., Science, 107, 873 (1948).

${ }^{3}$ Humfeld, H., and Sugihara, T. F., Food Technol., 3, 355 (1949).

- Humfeld, H., and Sugihara, T. F., Mycologia, 44, 605 (1952).

5 Sugihara, T. F., and Humfeld, H., App. Microbiol., 2, 170 (1954).

- Moustafa, A. M., App. Microbiol., 8, 563 (1960).

' Reusser, F., Spencer, J. F. T., and Sallans, H. R., App. Microbiol., $6,1(1958)$.

Bels, P. J., Horst, Holland (personal communication).

'Block, S. S., Mushroom Sci., 4, 287 (1959).

\section{MISCELLANEOUS}

\section{Publication of Proceedings of Conferences and Symposia}

I HAVE read with the greatest interest and indeed gratitude the remarks of Sir Lindor Brown concerning the publication of proceedings of conferences and symposia, and the editorial comments on the same subject.1.

Much of the trouble I believe arises because, as Sir Lindor points out, complete publication of a symposium is sometimes achieved only one or two years after the event; in consequence, the report is out of date when it appears, and few of those who presented papers have been able to resist the temptation to publish their material elsewhere. But this delay, though unfortunately common, is quite unnecessary. Some years ago I attended a symposium on biological problems of grafting in Liège, which I had hoped would have served as a model for the future. Communications had to be submitted a few weeks before the symposium, and when we arrived they were all in galley proof. Each participant received a proof of his own contribution with firm instructions to correct it immediately and return it to the secretariat. The discussion was taken down more or less verbatim, typed, and distributed to participants just after dinner each evening. We were then expected to edit our own discussion and return an acceptable version to the secretariat of the conference by breakfast time the following morning. The result was that when we left Liège all the contributed articles were set up in type, and the discussion was ready to go to the printers. Publication of the report of the symposium was not quite as quick as had been hoped; but the delay was partly due to the fact that two languages were used at the meeting. I should have thought that if this pattern were followed at a meeting where only one language was used it should be possible to have an official report of the symposium on sale 4-6 weeks after the meeting.

I fully agree with the view that there should be many symposia of which no reports are published; clearly, however, publication is sometimes worth while, and in this event it should, and could, be done quickly.

\footnotetext{
Department of Surgical Science, University New Buildings, Teviot Place, Edinburgh.

1 Nature, 198, 709, 724 (1962).
} 